\title{
Brief Report \\ Brief Report: Use of non-pharmacological strategies for pain relief in addiction treatment patients with chronic pain ${ }^{1}$
}

Running head: Use of non-pharmacological treatments for pain

Lewei (Allison) Lin 0000-0003-2765-7814, M.D. ${ }^{1,2}$, Amy S.B. Bohnert, Ph.D. ${ }^{1,2}$, Mary Jannausch, M.S. ${ }^{2}$, Jenna Goesling, Ph.D. ${ }^{3}$, Mark A. Ilgen, Ph.D. ${ }^{1,2}$

${ }^{1}$ Addiction Center and Mental Health Services, Translations and Outcomes Program, Department of Psychiatry, University of Michigan, 2800 Plymouth Rd, Bldg 16, Ann Arbor, MI 48109

${ }^{2}$ VA Center for Clinical Management Research (CCMR), Department of Veterans Affairs Healthcare System, Ann Arbor MI, North Campus Research Complex, 2800 Plymouth Rd Ann Arbor, MI 48109

${ }^{3}$ University of Michigan, Department of Anesthesiology, Back \& Pain Center, 325 E. Eisenhower Parkway, Ann Arbor Michigan, 48108

Lewei (Allison) Lin M.D. (corresponding author)

University of Michigan, Dept. of Psychiatry

2800 Plymouth Rd Bld. 16 Fl. 2

Ann Arbor, MI 48109

Phone: 734-764-0231

Email: leweil@med.umich.edu

\footnotetext{
1 This is the author manuscript accepted for publication and has undergone full peer review but has not been through the copyediting, typesetting, pagination and proofreading process, which may lead to differences between this version and the Version of Record. Please cite this article as doi:10.1111/ajad.12600
} 
Abstract

100

Narrative: words: 1493

Number of Tables: 1

Number of Figures:0

Number of References: 10

Abstract

Objectives: We examined use of non-pharmacological treatments for pain in addiction treatment patients. Methods: Patients in addiction treatment with chronic pain $(\mathrm{N}=501)$ were classified based on use of non-pharmacological pain treatments. Demographic and clinical correlates were compared.

Results: $49 \%(\mathrm{~N}=243)$ of patients used a non-pharmacological treatment in the past year vs. $72 \%$ $(\mathrm{N}=361)$ who used opioids. Non-pharmacological treatment users were more likely to use opioids and other pain medications. Conclusions: Non-pharmacological treatments are less commonly used than opioids by addiction treatment patients. Scientific Significance: Findings highlight the need to better understand pain treatment decision-making among addiction treatment patients. 


\section{Introduction}

Among those with chronic pain and substance use disorders (SUDs), the use of prescription opioids in particular pose increased risk for opioid use disorders, and overdose ${ }^{1,2}$ However chronic pain remains prevalent so it is important to determine if non-medication treatments are feasible and appealing especially for people with chronic pain and comorbid addiction. Current best practice guidelines, including the recent CDC guidelines on opioid prescribing for chronic pain, recommend incorporating non-pharmacological strategies for treating chronic pain. ${ }^{3}$ However, few studies have examined utilization of these treatments in SUD patients. These studies have focused on patients receiving treatment for opioid use disorders and only some with current chronic pain. ${ }^{4,5}$ Although that is an important subgroup, it may not generalize to patients with ongoing chronic pain across a spectrum of SUDs.

The aim of the current study was to characterize use of non-pharmacological treatments for pain and examine correlates of non-pharmacological treatment use in a large sample of patients with chronic pain in residential addictions treatment. We used screening and baseline data from patients recruited for a randomized trial of cognitive behavioral therapy (CBT) for pain and addiction. The term nonpharmacological treatments was specifically used to refer to use of non-medication and non-surgical interventions for pain treatment. Use of physical therapy, meditation/yoga, acupuncture, psychotherapy, and herbal supplements were specifically assessed in this study.

\section{Methods}

\subsection{Participants and procedures}


Data come from a sample of adults recruited at a large residential addiction treatment program in southeastern Michigan from October 2011 to July 2014. Clients ages >18 receiving services at the treatment site were eligible to participate in the screening portion of the study.

Participants who met criteria for moderate to severe chronic pain on the self-report screening survey, defined by an average rating of the participant's usual and worst pain over the prior 3 months of 4 or greater on the Numeric Rating Scale of Pain Intensity (NRS-I) ${ }^{6}$ were eligible to participate in a randomized controlled trial assessing impact of CBT on treatment of comorbid pain and SUD. ${ }^{7}$ Patients who endorsed acute suicidality or psychoses, or those unable to provide written consent were excluded from participation. Data from participants' baseline and screening surveys were used in these crosssectional analyses. Study procedures were approved by the University of Michigan Medical School Institutional Review Board.

\subsection{Measures}

\subsubsection{Pain}

Pain intensity over the past 3 months was assessed using an 11-point numeric rating scale ranging from 0 (no pain at all) to 10 (worst pain imaginable). This measure has external validity and can detect clinically meaningful changes in subjective measure of pain intensity. ${ }^{6}$ Participants were asked to provide ratings on their usual pain over the past 3 months and overall duration of their pain. Participants were asked about use of "other prescription pain medications in the past year" and use of "over the counter pain medications in the past year." The Chronic Pain Acceptance Questionnaire assessed pain acceptance, a psychological construct that is an important correlate of functioning in patients with chronic pain. ${ }^{8}$ 


\subsubsection{Use of non-pharmacological treatments}

Participants were asked "in the past year, have you received any of the following treatments for your pain" and response options included: physical therapy, meditation/yoga, acupuncture, psychotherapy, and herbal supplements.

\subsubsection{Substance Use}

Severity of substance use was assessed using the Alcohol, Smoking, and Substance Involvement Screening Test (ASSIST), a self-report measure of substance use and related problems. ${ }^{9}$ Specific substances examined were opioids (including both prescription opioids and heroin), alcohol, cocaine, and marijuana. Based on previous literature, ${ }^{9}$ patients who met criteria for moderate (score 4-26) or high (score $\geq 27$ ) severity of use for each of the four substances above were categorized as likely having a SUD for that substance.

\subsubsection{Depression}

Depression was assessed using the Patient Health Questionnaire (PHQ-9), a self-administered measure of depressive symptoms. Participants were asked to rate on a four-point scale from 0 (not at all) to 3 (nearly every day) how often each of the symptoms bothered them during the past two weeks.

\subsection{Data Analyses}

Patients were divided into those who reported utilizing any non-pharmacological treatment vs. no use of non-pharmacological treatments in the past year. Bivariate comparisons of demographic and clinical characteristics were assessed across these categories using chi-square tests for categorical 
variables and the t-test for continuous variables. Supplementary analyses adjusted for demographic characteristics (age, gender, race and ethnicity).

\section{Results}

\subsection{Sample characteristics}

In total, 501 adults in residential addiction treatment were included. Table 1 shows $49 \%$ ( $N=243)$ of this sampled reported any past year use of non-pharmacological treatments for pain. The average pain level was 6.7 (SD 1.7) on a scale of 0 to $10 ; 89 \%$ of this sample endorsed pain lasting for more than one year.

\subsection{Non-pharmacological treatment}

There were no significant differences when comparing past year non-pharmacological treatment users and non-users on gender, marital status or employment status. Non-pharmacological treatment users were significantly more likely to be White $(78 \%, \mathrm{~N}=190)$ and more likely to have some college education $(22 \%, \mathrm{~N}=54)$ compared to people who did not utilize these treatments, although the absolute difference was modest (74\% White, $\mathrm{N}=192$ and 14\%, N=36 with some college education). There were no differences between groups on average pain intensity or duration of pain.

In terms of specific treatments, $22 \%$ of the sample $(\mathrm{N}=110)$ used physical therapy, $19 \%(\mathrm{~N}=97)$ used meditation or yoga, 16\% (N=82) used psychotherapy, 15\% (N=76) used herbal remedies, and 6\% $(\mathrm{N}=31)$ used acupuncture in the past year to help alleviate pain.

\subsection{Use of pain medications}

This article is protected by copyright. All rights reserved. 
In this sample, 53\% ( $\mathrm{N}=266)$ of participants reported using prescribed opioid pain medications and $56 \%(\mathrm{~N}=279)$ reported using opioid pain medications without a prescription in the past year (see Table 1). People who used non-pharmacological treatments for pain also had higher levels of prescribed opioid medication use $(65 \%, \mathrm{~N}=159)$, any opioid use prescribed or not $(81 \%, \mathrm{~N}=198)$, and other nonopioid prescription pain medications $(79 \%, \mathrm{~N}=193)$ compared to people who did not use nonpharmacological treatments (41\%, N=107 for prescribed opioids, $63 \%, \mathrm{~N}=163$ for opioids prescribed or not, $61 \%, \mathrm{~N}=158$ for other prescription pain medications).

\subsection{Substance use disorders}

Participants who used non-pharmacological treatments were more likely to meet possible criteria for an opioid use disorder or cannabis use disorder, but not stimulant use disorder or alcohol use disorder.

Supplementary analyses adjusted for demographic characteristics. Results were generally consistent, except that depression and opioid use disorder were no longer significant between the two groups.

\section{Discussion}

This study is one of the first to examine prevalence of using non-pharmacological strategies for pain relief among patients in addiction treatment with chronic pain. Almost half of participants endorsed past year use of non-pharmacological treatments for pain relief but almost three quarters of these patients used opioid pain medications (prescribed or non-prescribed) in the past year. 
Patients who used non-pharmacological treatments for pain were also more likely to use prescribed opioids and prescribed non-opioid pain medications in the past year, though their average pain level was not significantly different from those who did not use non-pharmacological treatments. It is possible that patients who use opioids are more likely to use non-pharmacological treatments to relieve a higher perceived burden from pain. Alternatively, those who reported use of non-pharmacological treatments may represent a more treatment resistant sample who have tried numerous treatments without clear benefit. Further research could focus on perceived effectiveness of non-pharmacological treatments for pain relief among patients with SUDs and longitudinal studies may clarify if non-pharmacological treatments helps reduce use/misuse of opioids over time.

Overall, only a small minority of patients utilized specific non-medication strategies in the past year despite having ongoing pain symptoms. As one example, although physical therapy was the most commonly used non-pharmacological treatment in our sample, use was still less than that found in a population based survey of people with chronic pain. ${ }^{10}$ Given the high level of pain symptoms and active SUD, current level of use is lower than expected. In addition, limited insurance coverage for nonpharmacological non-surgical interventions and limited availability may limit patient access to these treatments.

There are a number of important limitations to this study. Assessment of non-pharmacological treatment modalities was not exhaustive. However, we focused on treatments that have been commonly used in prior addiction samples, ${ }^{4}$ and shown to be helpful for pain. The study did not specifically assess whether the pain was withdrawal-related but the 3-month window used to identify chronic pain makes it unlikely that withdrawal fully accounted for pain. These analyses were cross-sectional and based only 
on self-report so self-report bias is possible. We cannot infer causality among variables studied in this analysis. Furthermore, data were collected at a single treatment site and analyses were limited to participants enrolled in a study of CBT for pain and addiction and may not generalize to other samples.

\section{Conclusions}

Patients in addiction treatment with chronic pain commonly use non-medication treatments for pain relief, but they use opioid pain medications more frequently.

\section{Acknowledgements}

We appreciate support for this study from National Institute on Drug Abuse (Rockville, MD) grant R01DA029587 (Ilgen). Dr. Lin received additional mentorship and training through the Research in Addiction Medicine Scholars (RAMS) Program (NIDA \#R25DA033211).

Declaration of interest: The authors report no conflicts of interest. The authors alone are responsible for the content and writing of this paper.

\section{References}


1. Edlund MJ, Martin BC, Russo JE, DeVries A, Braden JB, Sullivan MD. The role of opioid prescription in incident opioid abuse and dependence among individuals with chronic noncancer pain: The role of opioid prescription. Clin J Pain. 2014;30(7):557-564.

2. Bonar EE, Ilgen MA, Walton M, Bohnert AS. Associations among pain, non-medical prescription opioid use, and drug overdose history. Am J Addict. 2014;23(1):41-47.

3. Dowell D, Haegerich TM, Chou R. CDC guideline for prescribing opioids for chronic pain--united states, 2016. JAMA. 2016;315(15):1624-1645.

4. Barry DT, Beitel M, Cutter CJ, Joshi D, Falcioni J, Schottenfeld RS. Conventional and nonconventional pain treatment utilization among opioid dependent individuals with pain seeking methadone maintenance treatment: A needs assessment study. J Addict Med. 2010;4(2):81-87.

5. Barry DT, Savant JD, Beitel M, et al. Use of conventional, complementary, and alternative treatments for pain among individuals seeking primary care treatment with buprenorphine-naloxone. J Addict Med. 2012;6(4):274-279.

6. Farrar JT, Young JP,Jr, LaMoreaux L, Werth JL, Poole RM. Clinical importance of changes in chronic pain intensity measured on an 11-point numerical pain rating scale. Pain. 2001;94(2):149-158.

7. Ilgen MA, Bohnert AS, Chermack S, et al. A randomized trial of a pain management intervention for adults receiving substance use disorder treatment. Addiction. 2016;111(8):1385-1393.

8. Thompson M, McCracken LM. Acceptance and related processes in adjustment to chronic pain. Curr Pain Headache Rep. 2011;15(2):144-151. 
9. Humeniuk R, Ali R, Babor TF, et al. Validation of the alcohol, smoking and substance involvement screening test (ASSIST). Addiction. 2008;103(6):1039 1047.

10. Freburger JK, Carey TS, Holmes GM. Physical therapy for chronic low back pain in north carolina: Overuse, underuse, or misuse? Phys Ther. 2011;91(4):484-495. 
Table 1. Demographic and clinical characteristics of addiction treatment patients with chronic pain by utilization of non-pharmacological treatments for pain $(\mathrm{N}=501)$

\begin{tabular}{|c|c|c|c|c|}
\hline & $\begin{array}{c}\text { No use of non- } \\
\text { pharmacological } \\
\text { treatment } \\
(\mathrm{N}=258,51 \%)\end{array}$ & $\begin{array}{c}\text { Used non- } \\
\text { pharmacological } \\
\text { treatment } \\
(\mathrm{N}=243,49 \%)\end{array}$ & P-value & $\begin{array}{c}\text { Total } \\
(\mathrm{N}=501)\end{array}$ \\
\hline Age (Mean, SD) & $35.8(10.0)$ & $33.8(10.6)$ & 0.04 & $34.8(10.3)$ \\
\hline Male gender & $142(55 \%)$ & $118(49 \%)$ & 0.15 & $260(52 \%)$ \\
\hline Race & & & 0.02 & \\
\hline White & $192(74 \%)$ & $190(78 \%)$ & & $382(76 \%)$ \\
\hline African-American & $54(21 \%)$ & $32(13 \%)$ & & $86(17 \%)$ \\
\hline All others & $12(5 \%)$ & $21(9 \%)$ & & $33(7 \%)$ \\
\hline Hispamic ethnicity & $14(5 \%)$ & $13(5 \%)$ & 0.97 & $27(5 \%)$ \\
\hline Married/partmered & $54(21 \%)$ & $46(19 \%)$ & 0.56 & $100(20 \%)$ \\
\hline Education & & & 0.02 & \\
\hline Less than high school/GED & $63(24 \%)$ & $43(18 \%)$ & & $106(21 \%)$ \\
\hline High school or GED & $158(61 \%)$ & $146(60 \%)$ & & $304(61 \%)$ \\
\hline Some college or college grad & $36(14 \%)$ & $54(22 \%)$ & & $90(18 \%)$ \\
\hline Employment status & & & 0.14 & \\
\hline Regular full/part time, or retired & $40(16 \%)$ & $40(17 \%)$ & & $80(16 \%)$ \\
\hline Unemployed & $179(70 \%)$ & $149(63 \%)$ & & $328(66 \%)$ \\
\hline Disabled & $38(15 \%)$ & $49(21 \%)$ & & $87(18 \%)$ \\
\hline Depression level (Mean, SD) & $11.1(6.2)$ & $12.4(6.1)$ & 0.03 & $11.7(6.2)$ \\
\hline \multicolumn{5}{|l|}{ Substance use disorders } \\
\hline Opioid use disorder & $172(67 \%)$ & $188(77 \%)$ & 0.01 & $360(72 \%)$ \\
\hline Stimulant/cocaine use disorder & $167(65 \%)$ & $167(69 \%)$ & 0.34 & $334(67 \%)$ \\
\hline Camnabis use disorder & $141(55 \%)$ & $156(64 \%)$ & 0.03 & $297(59 \%)$ \\
\hline Alcohol use disorder & $189(73 \%)$ & $175(72 \%)$ & 0.76 & $364(73 \%)$ \\
\hline $\begin{array}{l}\text { Average pain in past } 3 \text { months } \\
\text { (Mean, SD) }\end{array}$ & $6.5(1.7)$ & $6.8(1.8)$ & 0.16 & $6.7(1.7)$ \\
\hline Duration of pain & & & 0.40 & \\
\hline 1 to 12 months & $30(12 \%)$ & $22(9 \%)$ & & $52(10 \%)$ \\
\hline$>1$ year to $10 \mathrm{yrs}$. & $181(70 \%)$ & $167(69 \%)$ & & $348(69 \%)$ \\
\hline$>10 \mathrm{yrs}$ & $47(18 \%)$ & $54(22 \%)$ & & $101(20 \%)$ \\
\hline Pain acceptance (Mean, SD) & $58.1(18.1)$ & $58.3(18.5)$ & 0.94 & $58.2(18.3)$ \\
\hline
\end{tabular}

This article is protected by copyright. All rights reserved. 


\begin{tabular}{|c|c|c|c|c|}
\hline \multicolumn{5}{|l|}{ Opioid medications } \\
\hline $\begin{array}{r}\text { Past year use of prescribed } \\
\text { opioids }\end{array}$ & $107(41 \%)$ & $159(65 \%)$ & $<.001$ & $266(53 \%)$ \\
\hline $\begin{array}{r}\text { Past year use of opioids without } \\
\text { prescription }\end{array}$ & $135(52 \%)$ & $144(59 \%)$ & 0.12 & $279(56 \%)$ \\
\hline Any past year opioid use & $163(63 \%)$ & $198(81 \%)$ & $<.001$ & $361(72 \%)$ \\
\hline \multicolumn{5}{|l|}{ Other pain medications } \\
\hline $\begin{array}{r}\text { Other prescription pain } \\
\text { medications (with or without } \\
\text { prescription) }\end{array}$ & $158(61 \%)$ & $193(79 \%)$ & $<0.001$ & $351(70 \%)$ \\
\hline $\begin{array}{r}\text { Over the counter pain } \\
\text { medications }\end{array}$ & $218(84 \%)$ & $216(89 \%)$ & 0.15 & $434(87 \%)$ \\
\hline
\end{tabular}

* p value from chi-square tests for categorical variables, and two-sided t-test for continuous variables 